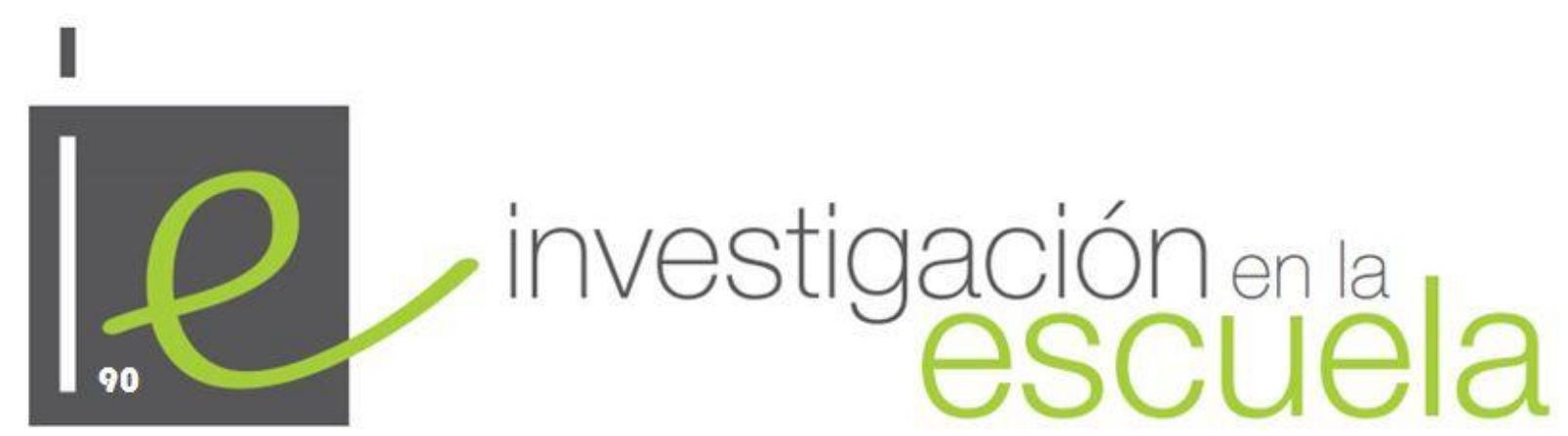

Revista académica evaluada por pares y de acceso abierto

\title{
Diseño y caracterización de un Proyecto de Indagación alrededor de la Evolución Humana y la Paleontología
}

Jordi Domènech-Casal

Universidad Autónoma de Barcelona

España

Citación: Domènech, J. (2016). Diseño y caracterización de un Proyecto de Indagación alrededor de la Evolución Humana y la Paleontología. Investigación en la Escuela, 90, 49-71. Recuperado de: http:// www.investigacionenlaescuela.es/articulos/R90/R90-4.pdf

Resumen: El uso de pruebas es un aspecto clave en la enseñanza de la Evolución Humana que incide también en la naturaleza del conocimiento científico. Se describe un Proyecto de Indagación sobre la Evolución Humana y Paleontología y se analiza a la luz de las dimensiones conceptual, procedimental y epistémica de la competencia científica. En ella, los alumnos crean marcos de interpretación de evidencias y los aplican en la creación e investigación de yacimientos arqueológicos, emulando el proceso de creación del conocimiento científico. Los resultados de la aplicación se discuten junto con una encuesta al alumnado en relación a las concepciones y habilidades científicas del alumnado.

Palabras clave: "Indagación"; "trabajo con fuentes primarias"; "contexto"; "Evolución Humana"; "ABP"

\section{Design and characterization of an Inquiry project around Human Evolution and Palaeontology.}

Abstract: Using evidences is a key aspect in teaching Human Evolution and understanding of the nature of science. We describe an Inquiry Project on Human Evolution and Palaeontology and we analyze its concerns regarding the conceptual, procedural and epistemic dimensions of Scientific 
Competence. Students construct and apply evidences interpretation frames in a role-playing activity that includes the creation and investigation of archeologic sites, reproducing the process of construction of scientific knowledge. The results of the application are discussed together with a survey in relation with students' conceptions and scientific skills.

Key words: "Inquiry"; "Working With Sources"; "context”; "Human Evolution”; "PBL”.

\section{Dessin et caractérisation d'un Projet d'enquête autour de l'Évolution Humaine et la Paléontologie.}

Resumè: L'usage d'évidences est un component clé dans l'enseignement de l'Évolution Humaine et participe aussi sur la nature du savoir scientifique. Nous décrivons un Projet d'Enquête sur l'Évolution Humaine et la Paléontologie et nous étudions ses liens avec les dimensions Conceptuelle, Procédurale et Épistémique de la Compétence Scientifique. Les élèves construisent des marcs d'interprétation d'évidences et les appliquent dans la création et recherche sur des gisements dans un jeu de rôle qui reproduit la création du savoir scientifique. Les résultats de l'application de l'activité et d'un sondage aux élèves sont discutés en rapport aux conceptions et habilités scientifiques des élèves.

Mosts clé: "Enquête"; "Travail avec des Sources Primaires"; "Contexte"; "Évolution Humaine"; "ABP".

\section{Introducción}

\section{La enseñanza de la evolución humana, un reto pendiente}

Desde el hallazgo de los restos del Australopithecus afarensis Lucy hasta los últimos estudios basados en filogenia molecular, el modelo explicativo que construye el estudio de la Evolución Humana de cómo hemos llegado hasta aquí ha ido cobrando solidez hasta considerarse un hecho probado. Aun así, son cada vez más frecuentes, en EEUU, pero también últimamente en Europa, corrientes fundamentalistas religiosas que tildan a la Teoría de la Evolución de "mera hipótesis" sin descender a lo que en Ciencia usamos para construir conocimiento, el uso de pruebas. En este sentido, varios trabajos muestran que los alumnos experimentan dificultades en el uso de pruebas para fundamentar modelos explicativos de la evolución (Puig y Jiménez-Aleixandre, 2009, Barberá, 2009) y que la enseñanza de la evolución humana en particular se produce de un modo excesivamente lineal y desvinculada del método y epistemología de la ciencia (Gutiérrez, 2009). Al desconocimiento general del alumnado sobre la naturaleza de la ciencia (Fernández et al, 2002) se añaden concepciones erróneas específicas de la evolución humana (Grau y de Manuel, 2002) como que el chimpancé actual sea un antepasado de los humanos, o que exista una tendencia teleológica hacia un ideal encarnado por el Homo sapiens actual. Concepciones que se suman a las habituales sobre la evolución en general (García, Martínez y Tiburzi, 2009; Bermúdez, 2015), y son algunas veces transmitidas desde la escuela (Torreblanca, de Longui y Merino, 2009).

\section{Enseñar de ciencia y sobre la ciencia}

La formación de ciudadanos competentes científicamente, más allá de conocer o reconocer los principales modelos científicos, implica también su aplicación a la resolución de problemas, la adquisición de las habilidades y estrategias que conducen a la construcción del conocimiento científico (elaboración de hipótesis, diseño de experimentos, análisis de datos, comunicación de resultados,...) (Hodson, 1994, Pedrinacci et al, 2012) y la comprensión de los mecanismos y 
dinámicas sociales por los que la comunidad científica valida el conocimiento. En concreto, la OCDE define la competencia científica como la capacidad de usar el conocimiento científico para identificar problemas, adquirir nuevos conocimientos, explicar fenómenos científicos y sacar conclusiones basadas en pruebas sobre cuestiones relacionadas con la ciencia (OCDE, 2006).

El marco PISA propone la concreción de la Competencia Científica en tres dimensiones: conceptual, procedimental y epistémica. La dimensión conceptual abarca los conocimientos de ciencia (hechos, conceptos, teorías y modelos). La dimensión procedimental se ocupa de las prácticas y enfoques en los que se basa la investigación empírica (toma de datos, control de variables...), mientras que la dimensión epistémica se ocupa de la comprensión de la forma en que se genera el conocimiento científico y la función que desarrollan en la Ciencia las preguntas, observaciones, teorías, hipótesis, modelos y argumentos) (OCDE, 2013, Garrido y Simarro, 2014).

La Enseñanza de las Ciencias Basada en la Indagación (en adelante, ECBI) es un enfoque pedagógico de enseñanza de las ciencias que pone el acento en formular actividades investigadoras, y la instrumentalización de las habilidades de razonamiento científico por parte del alumnado para la construcción del conocimiento científico (Osborne y Dillon, 2008; Caamaño, 2012, Llewellyn, 2005). Las secuencias estándar de ECBI reproducirían el proceso científico de creación del conocimiento en la escuela, estructurándose en varias etapas (Bogner, Boudalis y Sotiriou, 2012): 1) Formular preguntas investigables 2) Dar prioridad a las evidencias 3) Analizar las evidencias 4) Formular una explicación basada en las evidencias 5) Conectar la explicación con el conocimiento científico 6) Comunicar y justificar la explicación 7) Reflexionar sobre el proceso y el aprendizaje.

\section{Una propuesta pedagógica}

El proyecto C3 (Creación del Conocimiento Científico) ${ }^{1}$ es un proyecto educativo de enseñanza de las ciencias que tiene por objetivo que los alumnos comprendan la naturaleza de la ciencia, desarrollen habilidades científicas y adopten una actitud crítica y constructiva sobre el conocimiento. El proyecto usa como herramientas principales el trabajo en contextos de creación del conocimiento, las actividades ECBI y los andamios lingüísticos (Domènech-Casal, 2015a). En el marco del Proyecto C3, se desarrollan actividades basadas en la metodología del trabajo por proyectos (ABP) (Grau, 2010) a las que se incorporan perspectivas de la ECBI. Estas actividades, llamadas Proyectos de indagación, son secuencias didácticas en las que:

- Se parte de una pregunta o reto externo (y concomitante) con el aprendizaje.

- Se usan metodologías investigadoras (diseño de experimentos, modelización...).

- Se trabaja en equipo y mediante la discusión a partir de evidencias y eventos de modelización y comunicación científica que promueven la reflexión epistémica.

- Se generan productos en formato científico.

- Existe un contexto de creación de conocimiento científico que instrumentaliza y conecta el currículum con el mundo real.

En este marco metodológico, se ha desarrollado y aplicado un Proyecto de indagación alrededor de la Evolución Humana. La actividad se ha desarrollado y aplicado y se han recogido evidencias del proceso con los siguientes objetivos:

- Testar la metodología ECBI en el contexto de la Evolución Humana.

- Describir las aportaciones de las actividades contextualizadas a las dimensiones de la competencia científica.

- Analizar las concepciones del alumnado alrededor de la Evolución Humana y la creación del conocimiento científico.

\footnotetext{
${ }^{1}$ Proyecto C3 (Creación del Conocimiento Científico): https://sites.google.com/a/xtec.cat/c3/home
} 


\section{Descripción de la secuencia}

La actividad se desarrolló y aplicó con un total de 76 alumnos de $4^{\circ}$ de ESO de la materia optativa de Biología y Geología durante dos cursos académicos (2013-2014 y 2014-2015) en el instituto de Vilanova del Vallès. En el primer año se aplicó sólo una parte de las actividades con 40 alumnos, de forma prospectiva, que fueron mejoradas y aplicadas con el resto de alumnos en el curso siguiente en su versión más completa que se describe en este artículo. En la secuencia didáctica resultante, titulada Armshtadt3Delta, los alumnos, distribuidos por equipos, diseñan yacimientos arqueológicos como enigmas para sus compañeros, y a su vez investigan un yacimiento creado por compañeros, culminando la actividad en un evento de comunicación científica en formato de presentación oral y la creación de un museo escolar de Evolución Humana. La actividad -cuyos materiales se ofrecen en inglés para su descarga libre ${ }^{2}$ y ser propuestos directamente a los alumnosse divide en varias etapas (ver Tabla 1), cada una con sus propios objetivos. A lo largo de la actividad se proponen a los alumnos distintos andamios didácticos de carácter lingǘstico en la forma de pautas, documentos para el registro y análisis de datos, plantillas, para promover el desarrollo de habilidades de razonamiento científico (elaborar hipótesis, identificar pautas, hacer predicciones a partir de modelos...), aprovechando la relación íntima entre las habilidades de razonamiento y las habilidades cognitivo-lingüísticas (argumentar, justificar, describir...) descrita por otros autores (Jorba, 1998, Prat, 1998, Sanmartí et al, 1999) que permite desarrollar las primeras mediante el trabajo en las segundas.

Tabla 1.

Representación de las etapas de la frecuencia.

\begin{tabular}{|c|c|c|c|c|}
\hline Etapa & Objetivo en la secuencia & $\begin{array}{l}\text { Objetivo de aprendizaje y } \\
\text { dimensión asociada } \\
\text { (Conceptual, Procedimental, } \\
\text { Epistémica) }\end{array}$ & $\begin{array}{l}\text { Organización } \\
\text { social }\end{array}$ & $\begin{array}{l}\text { Productos (en } \\
\text { todas las etapas: } \\
\text { Diario de } \\
\text { Excavación) }\end{array}$ \\
\hline $\begin{array}{l}\text { Introductoria } \\
\text { Introducción a } \\
\text { la Evolución } \\
\text { Humana y } \\
\text { Taller de } \\
\text { Paleontología. }\end{array}$ & $\begin{array}{l}\text { Generar una actitud } \\
\text { proactiva ante el conflicto } \\
\text { cognitivo. } \\
\text { Despertar la inquietud por } \\
\text { indagar y el hábito de la } \\
\text { incertidumbre. }\end{array}$ & 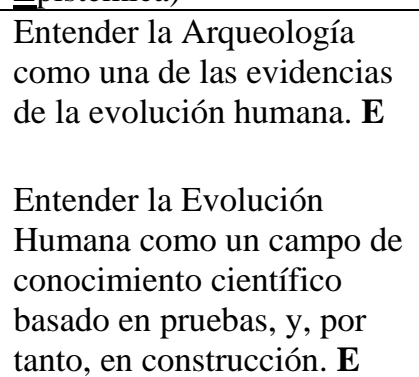 & Parejas & $\begin{array}{l}\text { Análisis del } \\
\text { Sitio: } \\
\text { Habitación. }\end{array}$ \\
\hline $\begin{array}{l}\text { 1.Creación de } \\
\text { fichas de } \\
\text { interpretación }\end{array}$ & $\begin{array}{l}\text { Crear fichas de } \\
\text { interpretación sobre } \\
\text { distintos tipos de } \\
\text { evidencias fósiles para su } \\
\text { uso en las etapas } \\
\text { posteriores. }\end{array}$ & $\begin{array}{l}\text { Identificar el origen de las } \\
\text { concepciones actuales sobre } \\
\text { distintos tipos de homínidos } \\
\text { en base a varios tipos de } \\
\text { evidencias. C, P, E. }\end{array}$ & $\begin{array}{l}\text { Grupos de } \\
\text { expertos }\end{array}$ & $\begin{array}{l}\text { Fichas de } \\
\text { interpretación. }\end{array}$ \\
\hline $\begin{array}{l}\text { 2. Diseño y } \\
\text { creación de un } \\
\text { yacimiento }\end{array}$ & $\begin{array}{l}\text { Usar las fichas de } \\
\text { interpretación para diseñar } \\
\text { y crear físicamente un } \\
\text { yacimiento con evidencias } \\
\text { como enigma para otro } \\
\text { equipo. }\end{array}$ & $\begin{array}{l}\text { Hacer predicciones a partir } \\
\text { de un modelo. } \mathbf{C}, \mathbf{P} \text {. }\end{array}$ & Equipos base & $\begin{array}{l}\begin{array}{l}\text { Fichas } \\
\text { descriptoras del } \\
\text { yacimiento. }\end{array} \\
\text { Evidencias } \\
\text { modeladas. }\end{array}$ \\
\hline
\end{tabular}

${ }^{2}$ Actividad Armshtadt3Delta https://sites.google.com/site/armshtadt3delta/home 
Continuación Tabla 1.

Representación de las etapas de la frecuencia

\begin{tabular}{|c|c|c|c|c|}
\hline Etapa & Objetivo en la secuencia & $\begin{array}{l}\text { Objetivo de aprendizaje y } \\
\text { dimensión asociada } \\
\text { (Conceptual, Procedimental, } \\
\text { Epistémica) }\end{array}$ & $\begin{array}{l}\text { Organización } \\
\text { social }\end{array}$ & $\begin{array}{l}\text { Productos (en } \\
\text { todas las etapas: } \\
\text { Diario de } \\
\text { Excavación) }\end{array}$ \\
\hline $\begin{array}{l}\text { 3. } \\
\text { Investigación } \\
\text { de un } \\
\text { yacimiento }\end{array}$ & $\begin{array}{l}\text { Usar las fichas de } \\
\text { interpretación para } \\
\text { investigar un yacimiento } \\
\text { creado por otro equipo. }\end{array}$ & $\begin{array}{l}\text { Saber colectar, describir y } \\
\text { catalogar pruebas y entender } \\
\text { la importancia de esos } \\
\text { procesos. P. } \\
\text { Sacar conclusiones de datos } \\
\text { en distintos formatos y } \\
\text { establecer niveles de } \\
\text { certidumbre de las } \\
\text { conclusiones. P. } \\
\text { Construir un modelo } \\
\text { explicativo de una situación } \\
\text { en base al conocimiento } \\
\text { actual sobre Evolución } \\
\text { Humana. C. P. }\end{array}$ & Equipos base & $\begin{array}{l}\text { Fichas } \\
\text { descriptoras del } \\
\text { yacimiento. } \\
\text { Ficha de análisis } \\
\text { de evidencias. }\end{array}$ \\
\hline $\begin{array}{l}4 . \\
\text { Comunicación } \\
\text { de los } \\
\text { resultados }\end{array}$ & $\begin{array}{l}\text { Hacer una síntesis del } \\
\text { proceso y comunicar los } \\
\text { resultados. Valorar el } \\
\text { proceso. } \\
\text { Generar un producto } \\
\text { visible del proceso. }\end{array}$ & $\begin{array}{l}\text { Comunicar científicamente y } \\
\text { argumentar en base a datos } \\
\text { en el marco de un modelo } \\
\text { científico. P. } \\
\text { Distinguir qué procesos y } \\
\text { dinámicas se establecen en } \\
\text { la construcción de un } \\
\text { modelo o teoría científico. } \\
\text { E. } \\
\text { Conocer los principios } \\
\text { básicos de museología y } \\
\text { comunicación científica. C, } \\
\text { P. }\end{array}$ & $\begin{array}{l}\text { Equipos base- } \\
\text { Gran grupo. }\end{array}$ & $\begin{array}{l}\text { Presentación } \\
\text { PowerPoint. } \\
\text { Exposición } \\
\text { física de } \\
\text { evidencias en } \\
\text { forma de } \\
\text { Museo. }\end{array}$ \\
\hline
\end{tabular}

\section{Etapa Introductoria: la arqueología en un contexto cercano}

En esta primera etapa, se propone al alumnado una imagen de una habitación del siglo XX. Partiendo de la observación de los elementos, los alumnos, en equipos de 3 alumnos, deben intentar establecer varias informaciones (edad, género, oficio, aficiones,...) sobre quién habita la casa y establecer el nivel de certeza de sus conclusiones (Figura 1). Junto con la imagen, se proporciona a los alumnos un andamio didáctico (Tabla 2) destinado a enseñar al alumnado a pautar los pasos por los que se asocia cada evidencia a una conclusión y el nivel de certeza de ésta. 


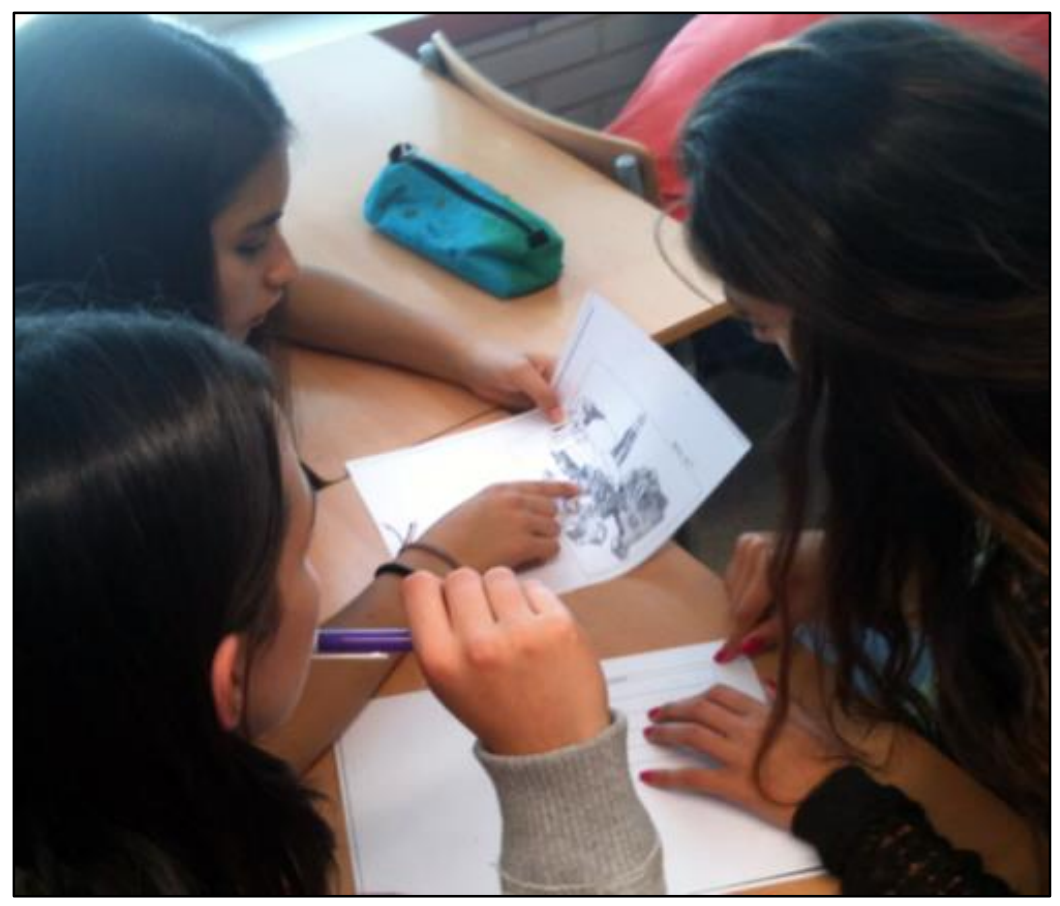

Figura 1. Los alumnos-as analizan la imagen en busca del habitante de la casa.

Tabla 2.

Andamiaje didáctico para el registro de conclusiones.

\begin{tabular}{|l|l|}
\hline Partiendo de la evidencia... & Iidentificar el objeto u objetos \\
\hline Que es una evidencia (sólida/débil) sobre su... & Edad/Género/Oficio/Aficiones/Peso \\
\hline $\begin{array}{l}\text { Consideramos que su [...] sería / estaría entre / } \\
\text { incluiría... }\end{array}$ & \\
\hline $\begin{array}{l}\text { Y consideramos que el nivel de certeza de esta } \\
\text { conclusión es... }\end{array}$ & $(0-100 \%)$ \\
\hline
\end{tabular}

Después de media hora de análisis, se hace una puesta en común en la que se analiza para cada ítem (edad, género...) las conclusiones a las que ha llegado cada grupo, en base a qué pruebas ha llegado a ellas y el nivel de certeza que atribuye a sus conclusiones. En la discusión se distingue entre conclusiones consensuadas y controvertidas y se pretende que el alumno entienda cómo funciona el razonamiento inductivo y la necesidad de compartir modelos interpretativos y establecer consensos y niveles de certeza.

\section{Etapa 1: Elaboración de un modelo consensuado para la interpretación de evidencias.}

Después de una introducción teórica a los distintos procesos clave (encefalización, migración, bipedestación, uso de herramientas, producciones culturales), líneas evolutivas y características morfológicas de distintas especies de homínidos ${ }^{3}$, se propone al alumnado construir y

\footnotetext{
${ }^{3}$ Los materiales para esa introducción teórica se presentan en el marco de un taller, y comprenden vídeos y una presentación oral, disponibles en: https://sites.google.com/site/armshtadt3delta/introduction-to-human-evolution
} 
analizar yacimientos arqueológicos correspondientes a las distintas especies humanas. Como paso previo, en esta etapa se elaboran marcos de interpretación compartidos, por lo que los alumnos se distribuyen en grupos de expertos de 4 alumnos. Cada grupo de expertos crea un marco interpretativo sobre uno de los tipos de evidencias, en el que incluye las características para ese tipo de evidencia en relación a 6 especies de homínidos determinadas, las mismas para todos los grupos de expertos ${ }^{4}$.

Tabla 3.

Tipos de evidencias y especies analizadas.

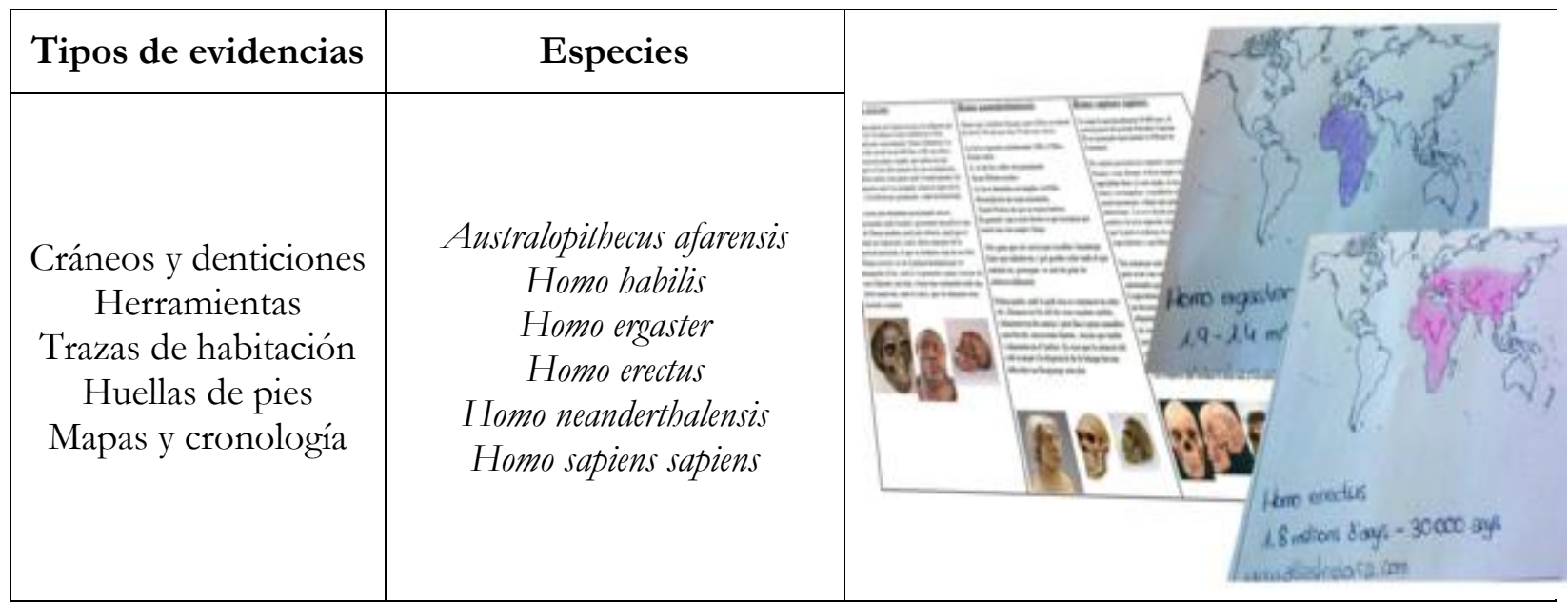

En esta etapa, los alumnos experimentan en primera persona la necesidad de elaborar marcos comunes y modelos de interpretación para poder trabajar en el marco de una comunidad de investigadores.

\section{Etapa 2: Diseño y creación de un yacimiento}

Los alumnos se agrupan en equipos (5-6 alumnos por equipo), procurando incluir expertos de distintos ámbitos en su equipo. Cada uno de estos equipos recibe el encargo de diseñar un yacimiento, con las siguientes instrucciones:

1. Deben escoger un homínido en particular de entre los seis propuestos y mantener en secreto su elección.

2. Deben diseñar 7 evidencias (fragmentos de cráneo, herramientas...), 6 de las cuales deben ser propias y características del homínido escogido y una discordante (pertenecer claramente a otro homínido distinto). La evidencias deben crearse a tamaño real en tres dimensiones usando pasta de modelar, yeso o similares.

3. Deben identificar con un número y una letra griega su yacimiento y crearlo físicamente: arar con azadas un espacio de $12 \mathrm{~m} 2$ (profundidad $15 \mathrm{~cm}$. aprox.) y enterrar en él las 7 evidencias, registrando en fichas ad hoc la naturaleza y ubicación de las evidencias en su yacimiento.

\footnotetext{
${ }^{4}$ Se ha usado el nombre Homo neanderthalensis en lugar de Homo sapiens neanderthalensis para evitar confusiones entre el alumnado y facilitar su búsqueda de información.
} 


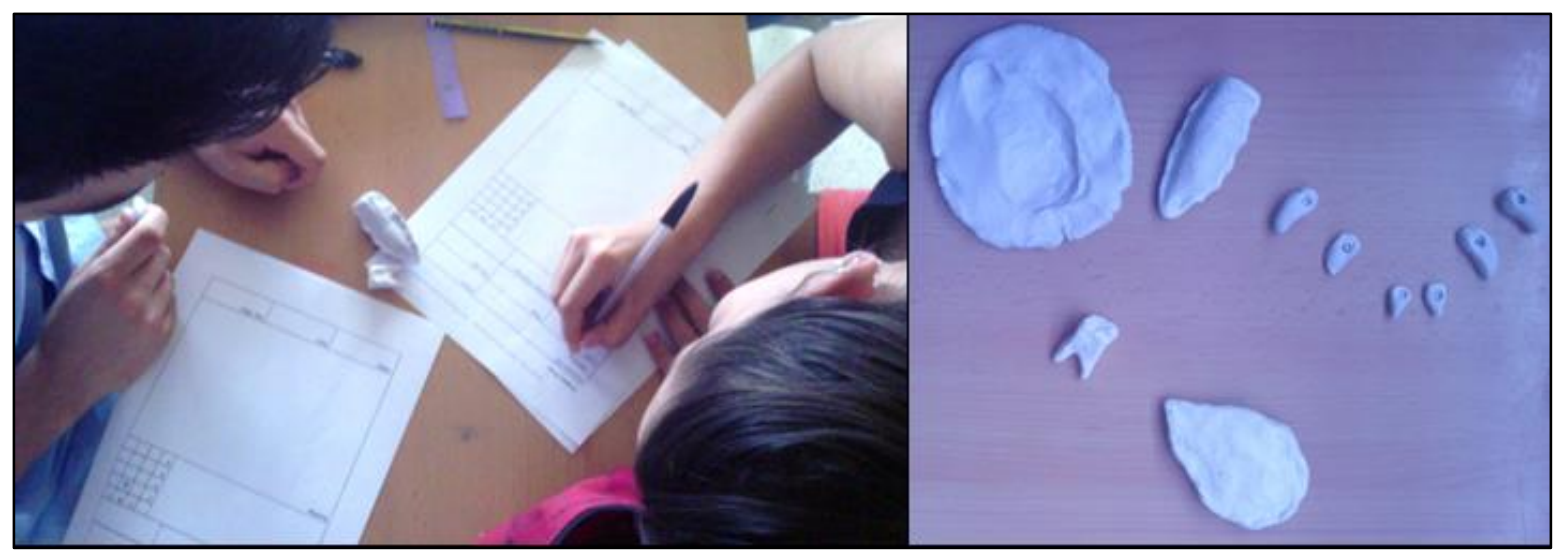

Figura 2. Análisis, tratamiento y registro de las evidencias.

Como apoyos para esta etapa, los alumnos disponen de los Marcos de Interpretación creados en la etapa anterior y deben rellenar dos tipos de fichas (organizadores visuales), un Site Grid -O mapa de localización de evidencias- y un Evidence Form -formulario de catalogación y descripción de evidencias- que imitan los formularios usados en arqueología para catalogar evidencias y dibujar mapas de los sitios arqueológicos ${ }^{5}$, fichas que presentan al profesor una vez preparado su yacimiento. Esta parte de la secuencia pretende que los alumnos realicen predicciones a partir de un modelo (razonamiento deductivo) estableciendo qué tipo de evidencias deberían encontrarse en un yacimiento del homínido elegido.

\section{Etapa 3: Investigación de un yacimiento}

En esta etapa, cada equipo analiza un yacimiento creado por otro equipo y lleva a cabo los procesos de excavación, recogida y catalogación de muestras. Para ello, los alumnos deben:

1. Demarcar el yacimiento en secciones de $1 \mathrm{~m} 2$ con la ayuda de fijaciones de madera y cordel blanco.

2. Excavar de forma sistemática de sección en sección, y recoger y catalogar cada una de las muestras que hallan.

3. De nuevo en el aula, analizar las muestras e intentar identificar el homínido al que se asocia el yacimiento y los datos discordantes/dudosos.

Los distintos yacimientos se crean yuxtapuestos en una zona poco usada, pero visible, del patio del centro educativo, generando interés y expectación en la comunidad educativa (Figura 3). A) alumnos recogiendo una punta de arpón en la sección 3D del yacimiento Armshtadt 4 Gamma registran y catalogan la evidencia. B) zona de yacimientos Armshtadt, con equipos en distintas fases de la excavación.

\footnotetext{
${ }^{5}$ Las fichas están disponibles en la web de la actividad: https://sites.google.com/site/armshtadt3delta/step-2
} 


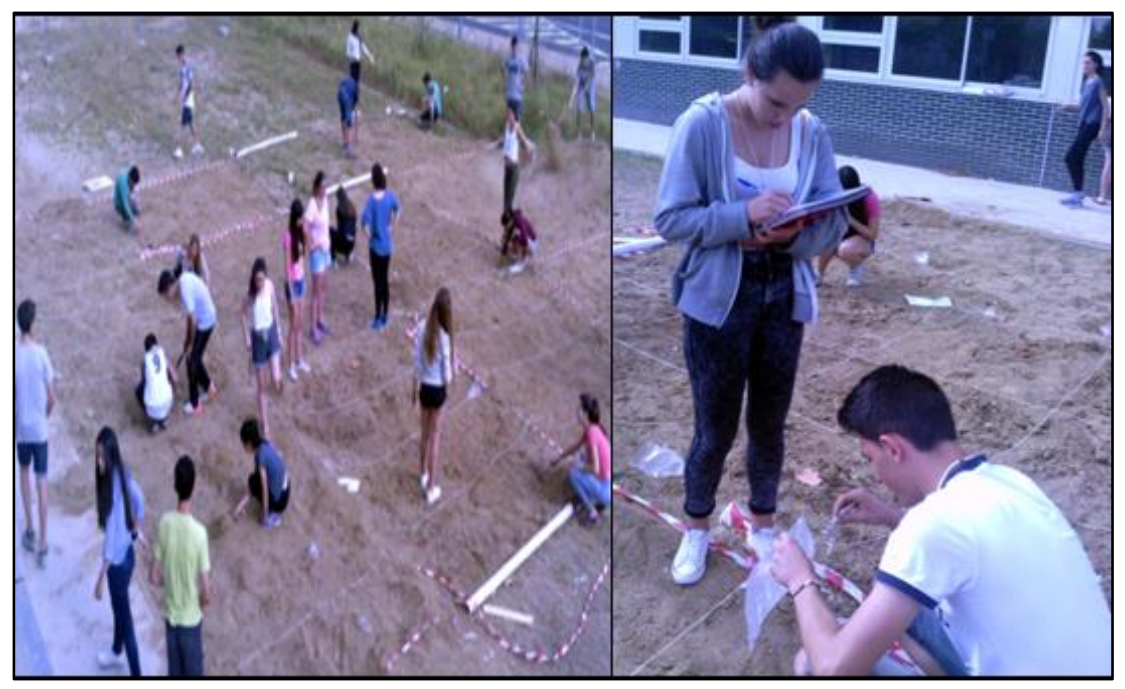

Figura 3. Zona de yacimientos y alumnos-as recogiendo evidencias

Además de las fichas de catalogación de evidencias, para apoyar al alumnado en su proceso de análisis, se le proporciona una Ficha de Análisis de Evidencias similar al usado en el análisis de la habitación en la primera etapa de la secuencia. En la ficha de análisis los alumnos deben justificar en base a las pruebas la identificación de uno u otro homínido y establecer si son evidencias sólidas o débiles (en base a si se pueden distinguir bien los rasgos de la evidencia, si la información que aportan permite excluir claramente otros homínidos...).

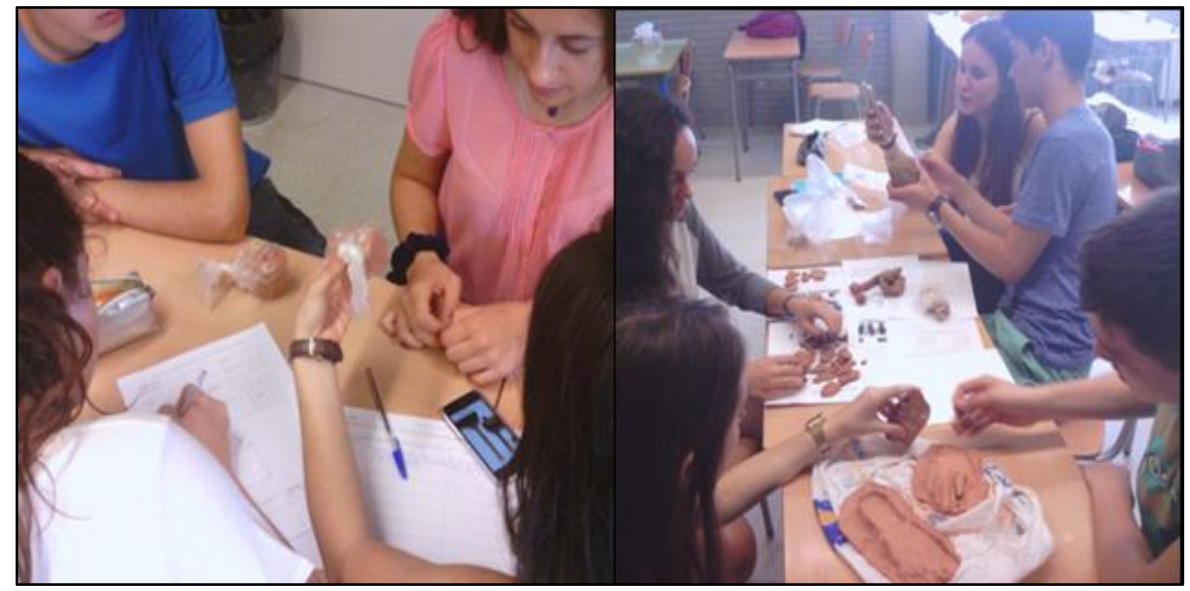

Figura 4. Análisis de las evidencias según los marcos de interpretación 
Tabla 4.

Marcos de interpretación

\begin{tabular}{|c|c|c|}
\hline La evidencia... & $\begin{array}{l}\text { Apoya la identificación de la } \\
\text { especie como... porque... }\end{array}$ & $\begin{array}{l}\text { Es una evidencia sólida / débil } \\
\text { porque... }\end{array}$ \\
\hline $\begin{array}{lll}\begin{array}{l}\text { Identificación } \\
\text { descripción }\end{array} & \text { (catálogo) } & \text { y }\end{array}$ & $\begin{array}{l}\text { Nombre de las especies posibles } \\
\text { y justificación en base a los } \\
\text { marcos de interpretación. }\end{array}$ & $\begin{array}{l}\text { Cuantificación de la información } \\
\text { que aporta la evidencia y la } \\
\text { certidumbre que se deriva en las } \\
\text { conclusiones. }\end{array}$ \\
\hline$\ldots$ & $\ldots$ & $\ldots$ \\
\hline
\end{tabular}

En esta etapa los alumnos aprenden los procesos de sistematización y precisión en la colección y análisis de datos y se percatan de la dificultad de extraer conclusiones a partir de datos incompletos.

\section{Etapa 4: Síntesis y comunicación científica}

Una vez terminado el análisis de las evidencias, y habiendo cada equipo realizado una primera identificación de a qué especie o especies atribuyen el yacimiento, el profesor aporta a los alumnos dos datos suplementarios sobre su yacimiento, idénticos para todos:

- La ubicación del yacimiento: alrededores de Jürmala, cerca de Riga, Letonia.

- La datación del yacimiento por técnicas químicas/espectrométricas: 1 millón de años $+/-300.000$ años.

Estos dos datos, en conjunción con el marco de interpretación de Mapas y cronologías, aportan nuevas informaciones a los alumnos, en algunos casos creando un conflicto entre las evidencias y los marcos de interpretación (especies más modernas de lo esperado, especies fuera de su zona de expansión...) que pueden resolverse reinterpretando los datos o cuestionando los marcos interpretativos. Los alumnos deben integrar en su modelo explicativo los tres tipos de datos obtenidos: evidencias del yacimiento (obtenidas y analizadas in situ) y localización del yacimiento y datación química del yacimiento (proporcionadas por el profesor).

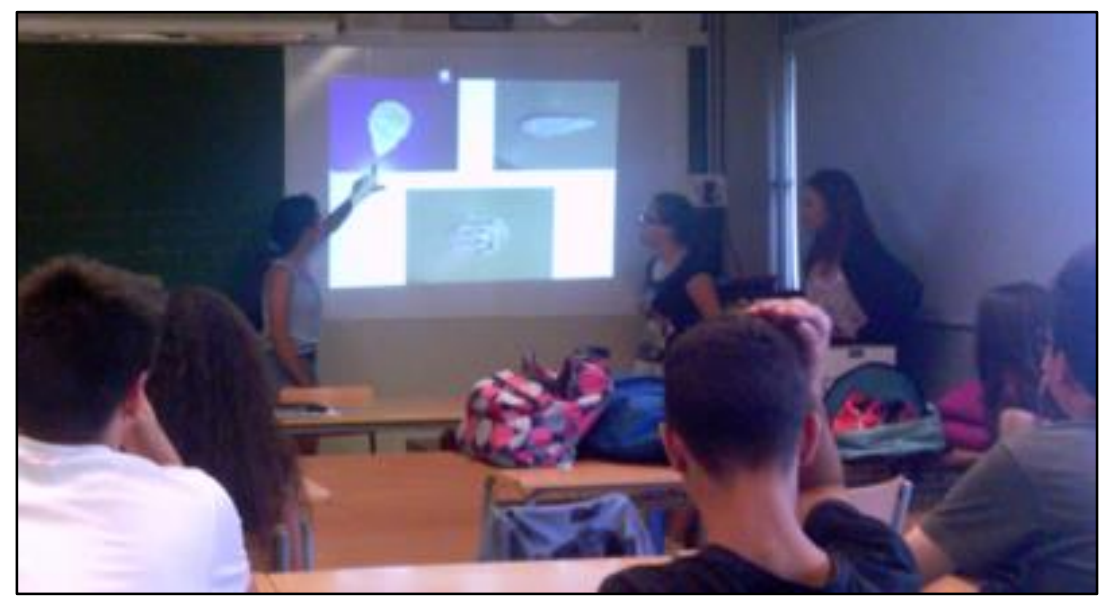

Figura 5. Debates durante las presentaciones orales. 
En esta etapa se pide a los alumnos que elaboren un modelo explicativo de sus datos y preparen una breve presentación oral defendiéndolo en base a las pruebas obtenidas. La presentación debe ofrecer una explicación geológica (pliegues, fallas, erosión, cursos fluviales, actividad de animales, etc.) a la presencia de evidencias discordantes en un mismo estrato. La actividad propone como conclusión la creación de un museo físico en el centro educativo, incluyendo evidencias recogidas junto con su interpretación e identificación (especie, tipo de evidencia,...). El grupo-clase debe seleccionar las piezas de mejor manufactura y mejor correspondencia con la etapa a la que representan, y los autores de las piezas seleccionadas deben elaborar una breve ficha de museización en la que se ofrezcan: 1) Especie y antigüedad (hipotética). 2) Descripción y justificación de la importancia de la evidencia. 3) Imagen o esquema de apoyo que ayude a identificar las partes/elementos significativos de la pieza o asociarlos a otros elementos conocidos. La exposición en forma de vitrina museizada en un espacio común y de paso del Centro supone una oportunidad de divulgación científica en el propio centro educativo.

Esta parte de la secuencia tiene por objetivo completar el ciclo de creación del conocimiento, fomentar la imagen de los museos como centros de interpretación y conectar la actividad con experiencias previas de los alumnos en museos reales. Esta parte de la secuencia se realizó de forma un tanto precipitada al ser final de curso, y no participaron en ella todos los alumnos, por lo que no se recogen datos más allá de la imagen descriptiva del producto final que acompaña este texto.

\section{Recogida y análisis de datos}

A lo largo de la actividad, se recogieron observaciones en el aula y producciones del alumnado como evidencias del proceso, además de recoger al final de la actividad en una encuesta las impresiones del alumnado sobre los cambios en sus concepciones. En la encuesta, se ha pedido al alumnado que valore su grado de acuerdo desde: 1) completamente en desacuerdo; 6) completamente de acuerdo) sobre varios ítems y representar su percepción de cambio en sus concepciones calificando también cuál considera que era su grado de aceptación antes de la actividad. Tanto en la encuesta como en la recogida de evidencias participaron 36 alumnos que habían llevado a cabo la actividad el curso 2014-2015.

\section{Resultados}

\section{Observaciones en la aplicación}

La actividad ha despertado el interés del alumnado, que ha participado con mucha implicación en su realización.

A lo largo de la etapa introductoria de análisis de una habitación como yacimiento, los alumnos perciben la "provisionalidad" y "incertidumbre" del conocimiento y el hecho de que siempre se interpreta a partir de modelos propios (qué tipo de ropa va asociada a qué edad, qué personas suelen practicar esquí...). Al pedir los alumnos al profesor la "respuesta correcta" se les ha explicado que en Ciencia no existe una "respuesta correcta" externa a la evaluación e interpretación de pruebas, lo que ha generado una situación de intenso debate en el aula, con algunos alumnos afirmando que, entonces, la ciencia es subjetiva. Esto ha generado un fructífero debate epistemológico para distinguir la concepción del conocimiento de "subjetivo" a "construido como consenso en base a pruebas". 
Las evidencias creadas por el alumnado han sido por lo general de gran calidad, optando en muchos casos por evidencias relativas a cráneos y mandíbulas, pisadas o herramientas. En algunos casos concretos, la rotura o deformación accidental de algunas piezas o la falta de pericia de los creadores del yacimiento ha generado piezas de difícil interpretación o identificación en la Etapa 3, lo que ha originado razonamientos hipotéticos para explicarlos y discusiones sobre el grado de certeza de cada hipótesis o su valor como prueba. Al estar entremezcladas con piedras y cúmulos de tierra y en algunos casos elaborados con materiales de color similar, los alumnos se han hallado en la situación real de intentar identificar cuál de los objetos visibles sería una evidencia: “¿Esto es una piedra 'normal' o una evidencia?'.

$\mathrm{Al}$ aportar en la etapa 4 los datos de localización y antigüedad de los yacimientos, como era de esperar, éstos han resultado ser discordantes con la mayoría de homínidos identificados. Algunos alumnos han usado los datos para reconsiderar su interpretación de las evidencias en función de la edad atribuida, y otros han concluido que los marcos interpretativos compartidos (el "consenso de la comunidad científica") eran incorrectos, pues éstos no se correspondían con los datos de su yacimiento, afirmando disponer de información suficiente como para cambiar lo que se pensaba hasta el momento: $\mathrm{H}$. erectus que habrían vivido o habitado en épocas distintas a las conocidas por la comunidad científica, H. ergaster de ubicación insólita... Las situaciones de conflicto han dado pie a discutir cuántos hallazgos discordantes serían necesarios para cambiar los marcos interpretativos, la naturaleza "democrática" o "dialógica" del conocimiento científico y el nivel de certeza/precisión de cada uno de los datos: evidencias físicas, métodos de datación química,...

Por lo que respecta a la evidencia discordante (evidencia de un período distinto que habrían incluido los alumnos en cada yacimiento/estrato), no se han identificado en todos los casos, y los alumnos han hallado dificultades para explicar las discordancias por procesos geológicos.

\section{Productos del alumnado y uso de andamios lingüísticos}

Los productos presentados por los alumnos han partido en todos los casos de andamios lingüísticos orientados específicamente a acompañar la construcción de razonamientos científicos y distinguir las pruebas de sus interpretaciones. El idioma original de las fichas (inglés) no ha supuesto un obstáculo para el alumnado. En ella los alumnos combinan un texto descriptivo, dibujo, ubicación en el yacimiento y distintas informaciones físicas ${ }^{6}$.

${ }^{6}$ Más producciones del alumnado en la web de la actividad:

https://sites.google.com/site/armshtadt3delta/didactic-guide 


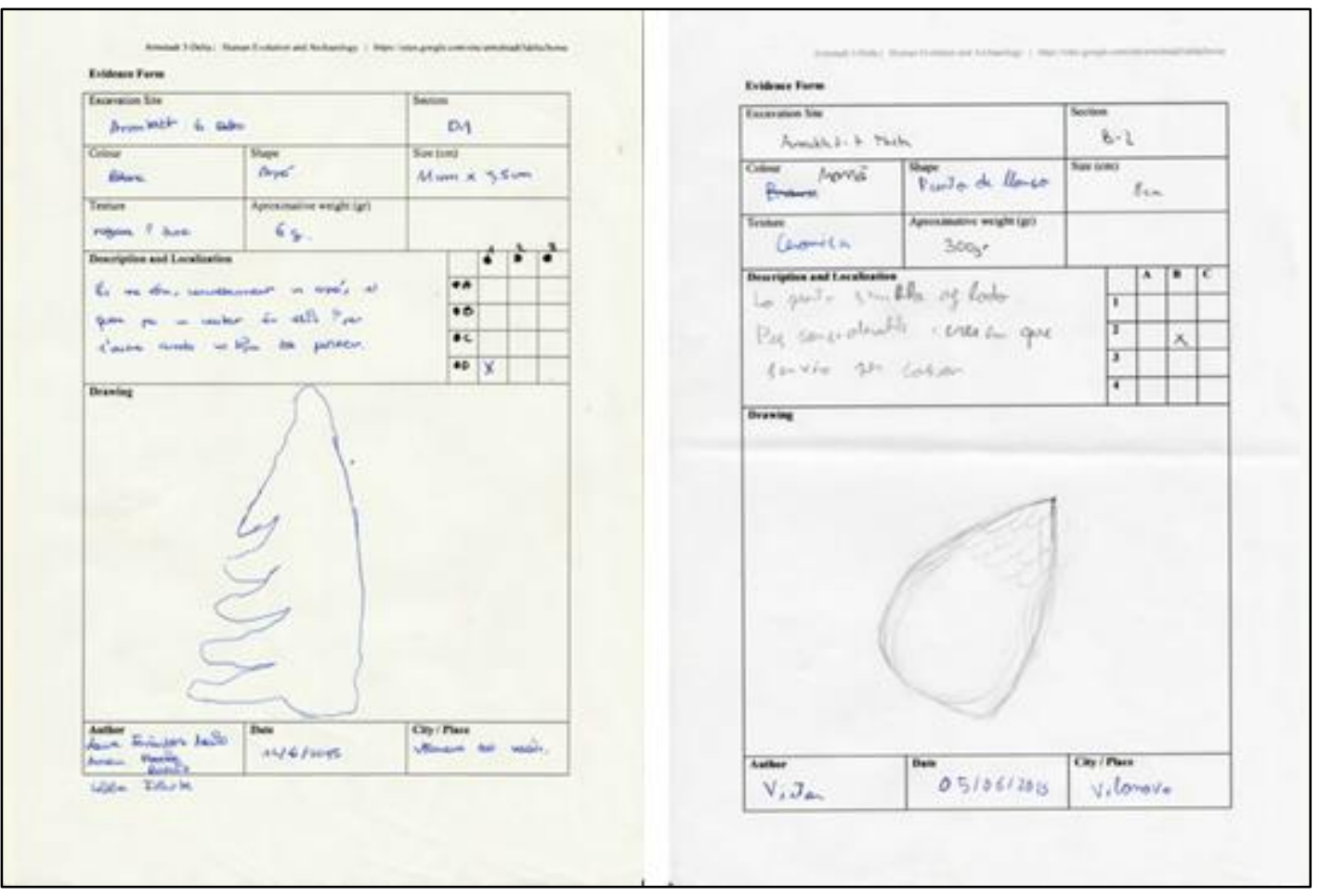

Figura 6. Fichas de catalogación de muestras realizadas por el alumnado.

En las fichas de análisis de evidencias, y en lo relativo al uso de pruebas, se han analizado dos aspectos: por un lado, la capacidad del alumnado de justificar su atribución a uno u otro homínido, y por el otro su capacidad de describir, justificándolo, si se trata de una evidencia fuerte o débil. De forma general, los alumnos justifican de forma completa la atribución a uno u otro homínido relacionando las pruebas con las características del homínido, describiéndolas ("porque el Homo sapiens no tenía arcos superciliares...”). Sólo en dos de las nueve fichas de análisis los alumnos muestran pocas habilidades al justificar, recurriendo a argumentos auto-referenciados ("Es erectus porque se le parece", "porque es como H. ergaster"), en lugar de justificaciones correctas ("Ergaster, porque la forma de la pisada muestra presión muy fuerte en la punta, y eso es típico de ese homínido").

En la siguiente ficha de análisis (Figura 7) se aprecian (enmarcados en línea continua) dos justificaciones bien formuladas: a) "Pertenece a H. sapiens, ya que el mentón está desarrollado y los dientes son pequeños y adaptados a una dieta muy variada"; b) "Esta evidencia no es muy clara, ya que algunos antecesores también usaban esas herramientas"). Y también se observan dos justificaciones mal formuladas, enmarcadas en línea punteada: a) "Es un H. sapiens, porque se corresponde con los registros que tenemos de las herramientas de H. sapiens"; b) "Es una evidencia clara, ya que hemos notado mucha diferencia con respecto a las otras”. Más producciones del alumnado en la web de la actividad: 


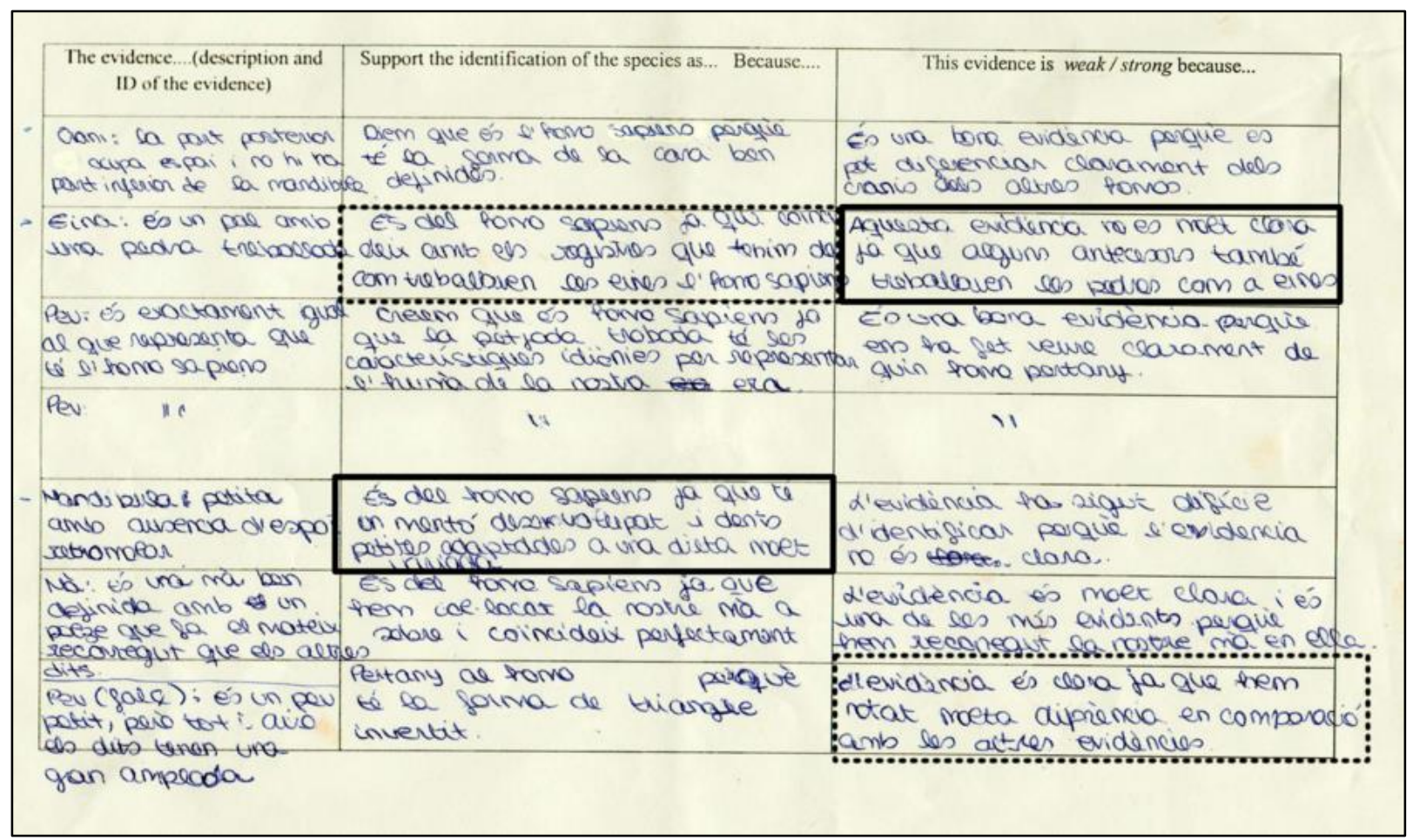

Figura 7. Ejemplo de ficha de análisis

En cambio, en lo referente a la justificación como evidencia fuerte o débil, son mayoría (6 de 9) los casos en que los alumnos enuncian simplemente su valor sin justificarlo, o recurren a justificaciones no productivas ("porque me ha hecho ver claro que lo era" "porque nos permite saber qué especie es") en lugar de justificaciones productivas ("Porque la forma es clara y definida y el mentón es específico sólo de los H. sapiens”).

$\mathrm{Al}$ ser valoradas por el alumnado en la encuesta, los alumnos han considerado las Fichas de Análisis como una herramienta útil, destacando su uso para "organizarse las ideas" y "sacar conclusiones de datos".

\section{Valoración del alumnado del aprendizaje de aspectos conceptuales, procedimentales y epistémicos.}

En los primeros 11 ítems de la encuesta sobre aprendizaje, los alumnos debían comunicar su percepción del cambio en sus concepciones contrastando su apoyo a cada frase antes y después de la actividad.

Tabla 5.

Primeros 11 items de la encuesta sobre aprendizaje

\begin{tabular}{|l|l|}
\hline ÍTEM & ENUNCIADO \\
\hline Ítem 1 & Los hombres actuales descienden de los monos \\
\hline Ítem 2 & Los seres vivos fueron creados tal como los conocemos ahora \\
\hline Ítem 3 & $\begin{array}{l}\text { Los diferentes homínidos han ido progresando hacia su forma más perfecta, el ser } \\
\text { humano }\end{array}$ \\
\hline
\end{tabular}


Tabla 5 (Continuación)

Primeros 11 items de la encuesta sobre aprendizaje.

\begin{tabular}{|l|l|}
\hline ÍTEM & ENUNCIADO \\
\hline Ítem 4 & La evolución cultural provocó un incremento de las capacidades cognitivas \\
\hline Ítem 5 & El incremento de las capacidades cognitivas provocó una evolución cultural \\
\hline Ítem 6 & La evolución humana se ha terminado \\
\hline Ítem 7 & Los cambios en la evolución de la especie han sido graduales y paulatinos \\
\hline Ítem 8 & $\begin{array}{l}\text { Los restos arqueológicos proporcionan información sobre la fisiología de los primeros } \\
\text { homínidos }\end{array}$ \\
\hline Ítem 9 & Los restos arqueológicos permiten establecer con seguridad su fisiología \\
\hline Ítem 10 & $\begin{array}{l}\text { Los restos arqueológicos proporcionan información sobre la cultura de los primeros } \\
\text { homínidos }\end{array}$ \\
\hline Ítem 11 & Los restos arqueológicos permiten establecer con seguridad su cultura. \\
\hline
\end{tabular}

Los ítems 1 y 6 identifican dos concepciones erróneas habituales, que habrían perdido apoyo a lo largo de la secuencia, aunque la primera mantiene como media un apoyo moderado incluso después de la secuencia. Mientras que los planteamientos creacionistas pierden el poco apoyo que tenían (Ítem 2), la visión teleológica de la evolución no sólo no ha descendido, sino que se ha incrementado ligeramente (ítem 3). Los ítems 8, 9, 10, 11 muestran que los alumnos entienden que las evidencias arqueológicas son informativas, pero no concluyentes en la interpretación de la cultura y fisiología de los homínidos, y que esa percepción se acentúa después de la secuencia.

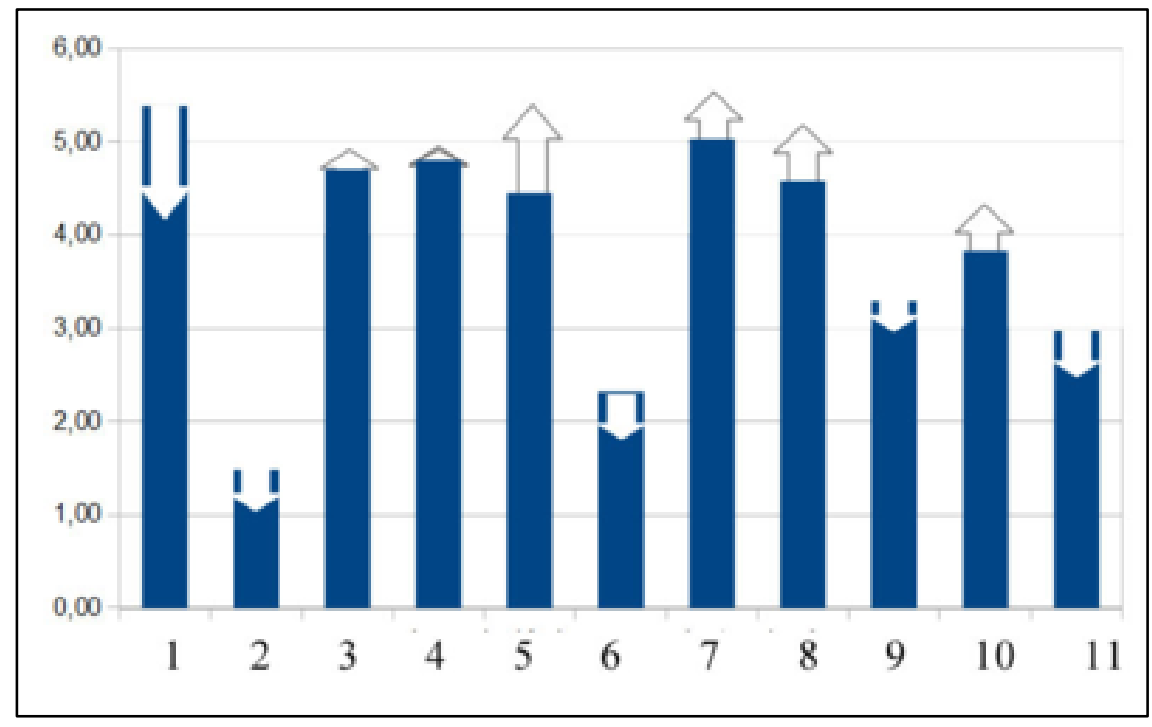

Figura 8. Cambio en las concepciones identificado por los alumnos antes y después de la actividad sobre distintos ítems (antes pensaba / ahora pienso).

Los alumnos consideran (Figura 11) que han desarrollado aspectos conceptuales y procedimentales en relación al estudio de la Evolución Humana (Tabla 5), destacando especialmente las habilidades de investigación y la distinción entre evidencias relevantes y no relevantes, fuertes y débiles (ítems 5, 6 y 9). Llama la atención el apoyo moderado que dan los alumnos al ítem 4 en relación al aprendizaje de los procesos de hominización. 
Tabla 6.

Ítems para la valoración de los contenidos trabajados.

\begin{tabular}{|l|l|}
\hline ÍTEM & ENCUNCIADO \\
\hline Ítem 1 & Los hechos y teorías importantes de la evolución \\
\hline Ítem 2 & Las características de cada homínido \\
\hline Ítem 3 & Una visión general de los procesos implicados (encefalización, bipedestación, migración...) \\
\hline Ítem 4 & Las causas de la evolución bumana \\
\hline Ítem 5 & Habilidades científicas de investigación (recoger datos, representarlos e interpretarlos, comparar muestras) \\
\hline Ítem 6 & Cómo recoger muestras; \\
\hline Ítem 7 & Cómo representar y describir datos; \\
\hline Ítem 8 & Cómo comunicar científicamente unas conclusiones; \\
\hline Ítem 9 & Distinguir entre evidencias relevantes y no relevantes, fuertes y débiles. \\
\hline
\end{tabular}

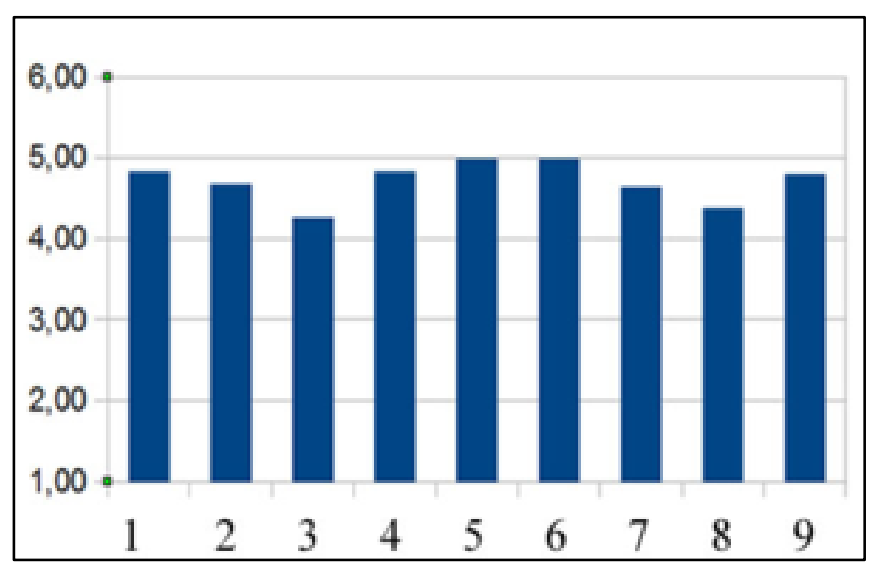

Figura 9. Valoración de los propios alumnos de su aprendizaje según los contenidos trabajados

Por otro lado, más del $80 \%$ del alumnado considera que la actividad ha sido de utilidad para aprender aspectos procedimentales/epistémicos como: Cómo hacen los científicos para decidir qué es cierto y qué no; Cómo construir un modelo explicativo a partir de datos diversos (morfología, mapas, antigüedad,...); Usar pruebas para argumentar un modelo explicativo; Decidir entre dos explicaciones posibles o Qué hacer cuando una prueba no se ajusta a un modelo global.

Y ronda el $70 \%$ de apoyo la utilidad de la actividad para aprender a: Hacer predicciones sobre cómo debería ser un yacimiento; Deducir a qué etapa pertenece un espécimen partiendo de datos diversos o Llegar a un consenso al discutir sobre datos con otros compañeros.

\section{Discusión y conclusiones}

\section{Las concepciones del alumnado y la Competencia conceptual. Enseñanza de la Evolución Humana y Currículum.}

Los alumnos valoran positivamente la actividad como herramienta para aprender los conceptos y modelos en la evolución humana y las distintas producciones del alumnado (especialmente la presentación oral) muestran un buen dominio de los procesos (bipedestación, 
encefalización, migración,...) implicados en la Evolución Humana y una comprensión aceptable de sus efectos y relaciones con aspectos ecológicos y fisiológicos.

Los alumnos descartan ya desde un inicio las interpretaciones creacionistas de la diversidad biológica, pero mantienen, incluso al final de la actividad, una concepción teleológica de la evolución. Además, algunas concepciones erróneas sobre la evolución humana (Los hombres actuales descienden de los monos; La evolución humana se ha terminado) ya observadas por otros autores (Grau y de Manuel, 2002) se reproducen en este caso y muestran una cierta resistencia a desaparecer aún después de la secuencia.

La secuencia promueve un aprendizaje mediado por lo que Bloom y otros (1956) identifican como actividades de alto nivel cognitivo, y que se enmarcan en la línea de la dimensión conceptual de la competencia científica según PISA (usar modelos para interpretar fenómenos...), evitando gimnásticas memorísticas en lo relativo a períodos temporales o características de cada una de las etapas.

Sin embargo, observamos con preocupación que no camina en esa línea el Currículum. De hecho, desaparecida la materia de Ciencias para el Mundo Contemporáneo, en la $\mathrm{LOMCE}^{7}$ el estudio de la Evolución Humana se refugia en las materias de Cultura Científica y Biología y Geología de $4^{\circ}$ de ESO con sendos escuetos estándares de evaluación: "Establece las diferentes etapas evolutivas de los homínidos hasta llegar al Homo sapiens, estableciendo sus características fundamentales, tales como capacidad craneal y altura", "Conocer las pruebas de la evolución y Reconocer y describir las fases de hominización" que invitan claramente a un aprendizaje memorístico sin ningún tipo de razonamiento, identificación de pautas o argumentación a partir de pruebas. Estos criterios promueven el mantenimiento de la desgraciada tendencia en el profesorado a "recorrer de puntillas" (Gutiérrez, 2009) y de forma excesivamente memorística y desvinculada del uso de pruebas esta parte de la ciencia.

Así mismo, el currículum LOMCE conserva las dificultades de currículums precedentes en lo que respecta a la contextualización de la evolución. En palabras del célebre genetista Theodosius Dobzhansky (1973): "Nada tiene sentido en biología si no es a la luz de la evolución". Sin embargo, la biodiversidad, la fisiología, la ecología y la genética (motores, materiales y consecuencias de la evolución) continúan tratándose de forma aislada de la evolución, lo que descontextualiza y hace menos relevantes a los aprendizajes.

\section{Las aportaciones de la aproximación ECBI y la contextualización a las Dimensiones Epistémica y Procedimental. Un esquema didáctico que reproduce el conocimiento científico.}

La secuencia establece varios pasos que construyen un rol y una narrativa del proceso para los alumnos (crear marcos de interpretación, crear un yacimiento, investigar el yacimiento creado por otro, comunicar las conclusiones de la investigación...) y ubican los contenidos en el conflicto cognitivo de algo desconocido (tal como sucede en la creación del conocimiento científico), reproduciendo las etapas estándar de la enseñanza mediante la indagación. Estas etapas han resultado escenarios útiles para el desarrollo de la Dimensión Procedimental de la competencia científica, pues los alumnos ejercitan las habilidades científicas básicas de razonamiento inductivo (elaborar un modelo explicativo a partir de observaciones al analizar un yacimiento), deductivo (realizar predicciones a partir de un modelo al crear un yacimiento), recogida y sistematización de

${ }^{7}$ LOMCE, Real Decreto 1105/2014, Boletín Oficial del Estado, Sábado 3 de enero de 2015, 169-546. 
datos (al colectar y catalogar evidencias), integración de datos de distintos tipos (antigüedad, localización, forma) y comunicación científica (en las presentaciones orales y la creación del museo).

En lo que respecta el uso de pruebas, los alumnos se muestran capaces de justificar la identificación de una evidencia con un homínido, pero muestran dificultades cuando se trata de establecer el valor de una evidencia como evidencia fuerte o débil.

La contextualización de la actividad en un marco realista, emulando un escenario de creación del conocimiento científico (paleontólogos en un yacimiento) ha provocado situaciones de interés desde el punto de vista de la dimensión epistémica, como la necesidad de generar consensos y establecer rangos de certeza en la comunidad científica (marcos interpretativos), la generación de situaciones serendípicas ${ }^{8}$ abiertas a soluciones o interpretaciones inesperadas (evidencias complejas, colisión entre marcos interpretativos y evidencias), o, como ejemplo más concreto, la necesidad de decidir qué hace que una evidencia sea fuerte o débil. La importancia de la contextualización y la orientación a la modelización es descrita por otros autores en la bibliografía (Sanmartí, Burgoa y Nuño, 2011; Simarro, Couso y Pintó, 2013) y se ha puesto en evidencia en esta actividad. El contexto propuesto al alumnado es rico y significativo en la materia y responde a tres de los ítems que otros autores proponen para "contextos" en enseñanza (Duranti y Goodwin, 1992, Gilbert, 2006): a) un escenario social, espacial y temporal en el que interaccionan ideas y eventos, b) un ambiente o marco conductual c) un uso del lenguaje específico. Aun así, el cuarto ítem (una relación con el conocimiento extra-situacional), que da relevancia al contexto, está poco desarrollado en la actividad y puede enriquecerse notablemente en esta secuencia.

\section{Herramientas didácticas y diseño de la actividad}

Los andamios didácticos permiten al alumnado desarrollar habilidades y estructurar su pensamiento. Esta secuencia aporta andamios de varios tipos: andamios lingüísticos (iniciadores de frase,...), de recogida y sistematización de datos (fichas de análisis y catalogación), dinámicas de trabajo en grupo (discusión y elaboración en grupo de comunicaciones científicas) y de reflexión metacognitiva colectiva (determinar el grado de certidumbre de conclusiones,...). Consideramos que estas herramientas han sido de utilidad para que los alumnos completaran con éxito la actividad y su aprendizaje. En particular, consideramos que el uso de andamios lingüísticos para la generación de textos breves y multiformato (imagen, argumentación, descripción) ha sido de utilidad no sólo para que el alumnado comunicara mejor sus razonamientos, sino para que los construyera mejor, algo ya descrito por otros autores (Jorba, 1998; Sanmartí, 2003) y que evidencian también los resultados de la encuesta.

La culminación de la actividad en la constitución de un museo escolar es una vía de conexión del alumnado con escenarios de creación y comunicación del conocimiento científico, y consideramos que este tipo de museos escolares es una vía de interés en el acercamiento del alumnado a la dimensión epistémica de la competencia científica y supone una oportunidad de divulgación y acercamiento al mundo de la ciencia y los museos en el propio centro educativo, como proponen otros autores (Carretero, 2010, Domènech-Casal, 2013, Collado, Collado y DomènechCasal, en publicación).

Como vías de desarrollo de la actividad, consideramos que deberían considerarse los siguientes aspectos:

- Conectar la propuesta con el uso de datos de secuencias de ADN para deducir filogenias, colaboraría a contextualizar la secuencia.

\footnotetext{
${ }^{8}$ https://www.significados.com/serendipia/
} 
- Incluir la lectura de artículos de prensa no especializada relativos a descubrimientos paleontológicos recientes y cercanos geográficamente supone una aportación a la relación con el conocimiento extra-situacional.

- La estructura y herramientas de la actividad permite adaptarla con relativa facilidad a temáticas distintas a la Evolución Humana, pero que comparten el trabajo con evidencias arqueológicas, como la Historia Medieval o Antigua.

- La actividad puede promover concepciones erróneas en relación a las formaciones geológicas: el tiempo que tardan en formarse pliegues o fallas en general puede superar el marco temporal de la Evolución Humana. Se incluyen en la actividad como transposición didáctica para enriquecerla a nivel curricular, pero implica errores en la percepción de los tiempos geológicos. Conviene tener esto en cuenta y hacerlo explícito al alumnado.

La actividad se enmarca en las actividades del proyecto educativo Proyecto C3 (Creación del Conocimiento Científico) $)^{9}$ y forma parte del Itinerario de Proyectos de Indagación

ProyectandoBioGeo ${ }^{10}$ que propone un recubrimiento del currículum LOMCE de la materia de Biología y Geología en 8 actividades de trabajo por proyectos de indagación.

La actividad ha sido catalogada en la Aplicació de Recobriment del Currículum (ARC) ${ }^{11}$ del Departament d'Ensenyament de la Generalitat de Catalunya. El lector encontrará de interés otras actividades similares del mismo Proyecto C3 sobre mitosis y cáncer o expresión génica e investigación biomédica (Domènech-Casal, en edición, en publicación), evolución, taxonomía y estratigrafía (Domènech-Casal, 2014) y deriva continental y tectónica de placas (Domènech-Casal, 2015b).

\section{Referencias}

Barberá, O. (2009). Extinción: una forma distinta de ver la vida. Alambique, Didáctica de las Ciencias Experimentales, 62, 29-42.

Bermúdez, G.M.A. (2015). Los orígenes de la Biología como ciencia. El impacto de las teorías de evolución y las problemáticas asociadas a su enseñanza y aprendizaje. Revista Eureka sobre Enseñanza y Divulgación de las Ciencias, 12(1), 66-90.

Bloom, B. S., Engelhart, M. D., Furst, E. J., Hill, W. H., \& Krathwohl, D. R. (1956). Taxonomy of educational objectives: The classification of educational goals. Handbook I: Cognitive domain. New York: David McKay Company.

Bogner, F., Boudalis, A., Sotiriou, S. (Eds.). (2012). Pathway. Best Practices of Inquiry-Based Science Education. Methods and Activities. Greece Epinoia: Pallini Attikis,

Caamaño, A. (2012). ¿Cómo introducir la indagación en el aula? Los trabajos prácticos investigativos. Alambique: didáctica de las ciencias experimentales, 70, 83-91.

Carretero, M. B. (2010). Nuestro centro como espacio divulgador de ciencia. Revista Eureka sobre Enseñanza y Divulgación de las Ciencias, 7(1), 127-136.

Collado, F., Collado, M., Domènech-Casal, J. (En prensa). WünderKammer Project: Un contexto museístico de enseñanza de la clasificación de los seres vivos. Alambique: didáctica de las ciencias experimentales.

\footnotetext{
${ }_{9}$ Proyecto C3 (Creación del Conocimiento Científico) https://sites.google.com/a/xtec.cat/c3/home

${ }_{10}$ ProyectandoGioGeo https://sites.google.com/site/proyectandobiogeo/

11 Aplicació de Recursos al Currículum http://apliense.xtec.cat/arc/node/30362
} 
Dobzhansky, T. (1973). Nothing in Biology makes sense except in the light of Evolution. American Biology Teacher, 35, 125-129.

Domènech-Casal, J. (2013). Los museos virtuales como recurso didáctico. Construyendo puentes digitales entre el museo y el aula. @TIC revista d'innovació educativa, 10, 92-100.

Domènech-Casal, J. (2014). Una secuencia didáctica de indagación y comunicación científica sobre taxonomía, evolución y estratigrafía. Alambique. Didáctica de las Ciencias Experimentales, 78, 5159.

Domènech-Casal, J. (En prensa). Proyecto C3: indagación científica, lengua y contextos en la ESO. Aula de Secundaria.

Domènech-Casal, J. (2015b). Una secuencia didáctica de modelización, indagación y creación del conocimiento científico en torno a la deriva continental y la tectónica de placas. Revista Eureka sobre Enseñanza y Divulgación de las Ciencias, 12(1), 186-197.

Domènech-Casal, J. (En prensa). Drug Research: una secuencia contextualizada de indagación sobre mitosis, cáncer y creación del conocimiento científico. Investigación en la escuela.

Domènech-Casal, J. (En prensa). Gene Hunting: una secuencia contextualizada de indagación alrededor de la expresión génica, la investigación in silico y la ética en la comunicación biomédica. Revista Eureka sobre Enseñanza y Divulgación de las Ciencias.

Duranti, A., Goodwin, C. (Eds). (1992). Rethinking context: Language as an interactive phenomenon. Cambridge: Cambridge, University Press

Fernández, I., Gil, D., Carrascosa, J., Cachapuz, A., y Praia, J. (2002). Visiones deformadas de la ciencia transmitidas por la enseñanza. Enseñanza de las Ciencias, 20 (3), 477-488.

García, S., Martínez, C., Tiburzi, M.C. (2009). Interpretando la evolución de los seres vivos. Alambique Didáctica de las Ciencias Experimentales, 67, 88-95.

Garrido A., Simarro, C. (2014). El nou marc d'avaluació de la competència científica PISA 2015: Revisió i reflexions didàctiques. Ciències, 28, 21-26.

Gilbert, J. K. (2006). On the nature of context in chemical education. International Journal of Science Education, 28 (9), 957-976.

Grau, R. (2010). Altres formes de fer ciència. Barcelona: Rosa Sensat.

Grau, R., y de Manuel, J. (2002). Enseñar y aprender evolución: una apasionante carrera de obstáculos. Alambique. Didáctica de las Ciencias Experimentales, 32, 56-64.

Gutiérrez, A. (2009). La evolución humana, demasiado humana. Alambique Didáctica de las Ciencias Experimentales, 62, 63-74.

Hodson, D. (1994). Hacia un enfoque más crítico del trabajo de laboratorio. Enseñanza de las Ciencias, 12 (3), 299-313.

Jorba, J. (1998). La comunicació i les habilitats cognitivo-lingüístiques. En Jorba, J., Gómez, I. y Prat, A. (Eds.). Parlar i escriure per aprendre. Ús de la llengua en situació d'ensenyament-aprenentatge de les àrees curriculars. Bellaterra: ICE de la UAB: 37-58.

Llewellyn, D. (2005). Teaching High School Science through Inquiry: A case study approach. Thousand Oaks, CA: Corwin Press \& NSTA press.

OCDE (2006). Marco conceptual para la evaluación PIS A 2006. París. OECD Pub. Service.

OCDE (2013). PISA 2015. Draft Science Framework. Rescatado de http://www.oecd.org/pisa/pisaproducts/Draft PISA 2015 Science Framework .pdf

Osborne, J., Dillon, J. (2008). Science Education in Europe: Critical Reflections. London: Nuffield Foundation.

Pedrinacci, E., Caamaño, A., Cañal, P., y de Pro, A. (2012). 11 ideas clave. El desarrollo de la competencia cientifica. Barcelona: Graó. 
Prat, A. (1998). Habilitats cognitivo-lingüístiques i tipologia textual. En J. Jorba, I. Gómez, y A. Prat, (Eds.). Parlar i escriure per aprendre. Ús de la llengua en situació d'ensenyament-aprenentatge de les àrees curriculars. Bellaterra: ICE UAB: 59-84.

Puig, B., Jiménez-Aleixandre, P. (2009). ¿Qué considera el alumnado que son pruebas de la evolución? Alambique, Didáctica de las Ciencias Experimentales, 62, 43-50.

Sanmartí, N. (Coord.). (2003). Aprendre ciències tot aprenent a escriure Ciència. Barcelona: Ed 62.

Sanmartí, N. Burgoa. B., y Nuño, T. (2011). Por qué el alumnado tiene dificultad para utilizar sus conocimientos científicos escolares en situaciones cotidianas? Alambique, Didáctica de las Ciencias Experimentales, 67, 62-69.

Sanmartí, N., Izquierdo, M., y García, P. (1999). Hablar y escribir. Una condición necesaria ara aprender ciencias. Cuadernos de Pedagogía, 281, 54-58.

Simarro, C., Couso, D., y Pintó, R. (2013). Indagació basada en la modelització: un marc per al treball pràctic. Ciències, 25, 35-43.

Torreblanca, M., De Longhi A.L., y Merino, G. (2009). Las jirafas no son como antes ¿Un mito de los libros de texto? Alambique. Didáctica de las Ciencias Experimentales, 62, 51-62.

\section{Recursos}

- Armshtadt3Delta https://sites.google.com/site/armshtadt3delta/home

- ProyectandoBioGeo https://sites.google.com/site/proyectandobiogeo/

- Proyecto C3 https://sites.google.com/a/xtec.cat/c3/

\section{Agradecimientos}

El autor agradece la colaboración del alumnado y profesorado del INS Vilanova del Vallès y el asesoramiento del experto en arqueología Ferran Díaz. Las experiencias contenidas en este artículo se enmarcan en la reflexión metodológica llevada a cabo en el grupo LIEC (Llenguatge i

Ensenyament de les Ciències) de la Universitat Autònoma de Barcelona -grupo de investigación consolidado (referencia 2014SGR1492) por AGAUR (Agència de Gestió d'Ajuts Universitaris i de Recerca) financiado por el Ministerio de Economía y competitividad (referencia EDU-2015-66643C2-1-P)-.

\section{Sobre el autor}

Autor: Jordi Domènech-Casal

Institución: Institut Marta Estrada (Barcelona); Grupo LIEC, Departamento de Didáctica de las Matemáticas y las Ciencias Experimentales, Universidad Autónoma de Barcelona.

E-mail: jdomen44@xtec.cat

Información biográfica: Jordi Domènech-Casal (1976) es Doctor en Biología y Licenciado en Humanidades. Entre los años 1999-2007 se dedicó a la investigación básica en genética molecular y química inorgánica (Universidad de Barcelona, Université París VII, Universitá di Bologna) y a la divulgación científica. Es Profesor de Secundaria desde 2008 (actualmente en el Institut Marta Estrada, Barcelona) y desde 2013 asesor de formación de profesorado en el Departament d'Ensenyament de la Generalitat de Cataluña. Coordina el grupo de trabajo de profesorado de ciencias EduWikiLab, el proyecto C3 de enseñanza competencial de las ciencias 
y el proyecto IndComp de evaluación interdisciplinar por competencias. Es miembro del grupo Llengua $i$ Ensenyament de les Ciències LIEC (Universitat Autònoma de Barcelona), profesor asociado en la misma Universidad y miembro del consejo asesor de la revista Cuadernos de Pedagogía. Ha publicado en varias revistas de ámbito nacional e internacional artículos alrededor de la auto-regulación de los aprendizajes, la Enseñanza de las Ciencias Basada en la Indagación y el Aprendizaje Basado en Proyectos.

https://jordidomenechportfolio.wordpress.com/

ORCID: orcid.org/0000-0002-7324-0000

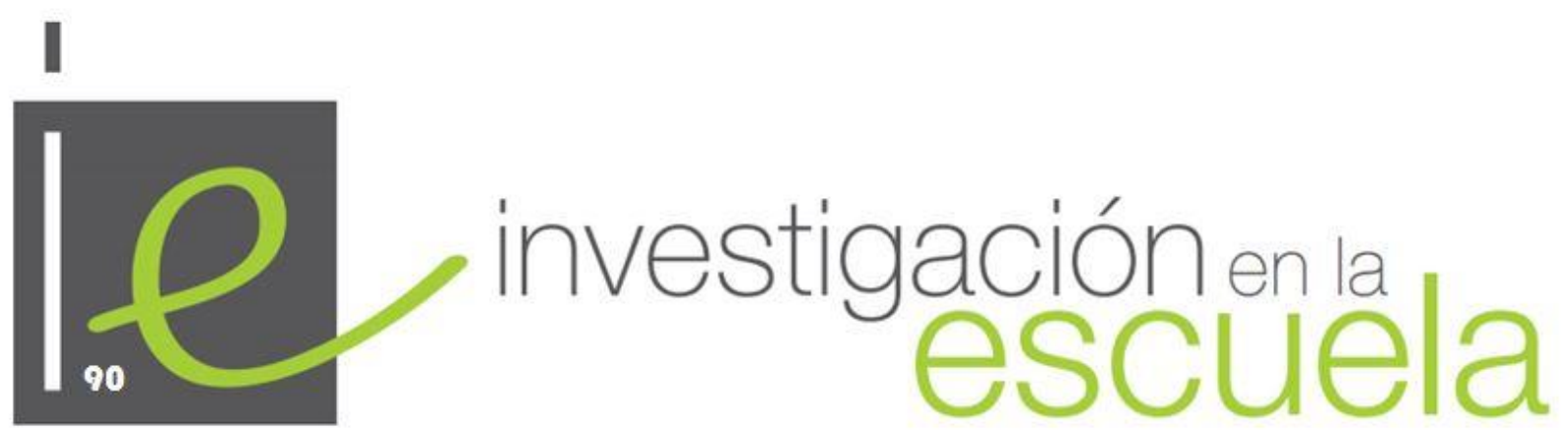

Revista académica evaluada por pares y de acceso abierto

Número $90 \quad 28$ de diciembre de $2016 \quad$ ISSN 2443-9991

\begin{abstract}
()
SOMERIIGHISRESERVED LOs/as lectores/as pueden copiar, mostrar, y distribuir este artículo, siempre y cuando se de crédito y atribución al autor/es y a Investigación en la Escuela, se distribuya con propósitos no-comerciales, no se altere o transforme el trabajo original. Más detalles de la licencia de Creative Commons se encuentran en http://creativecommons.org/licenses/by-nc-sa/3.0 Cualquier otro uso debe ser aprobado en conjunto por el autor/es, o Investigación en la Escuela.
\end{abstract}

Contribuya con comentarios y sugerencias en la web de la revista. Por errores y sugerencias contacte a investigacionescuela@,ddcc.uhu.es 


\section{Investigación en la escuela}

Consejo de dirección: Ana Rivero García (Universidad de Sevilla), Nicolás de Alba Fernández (Universidad de Sevilla), Pedro Cañal de León (Universidad de Sevilla), Francisco F. García Pérez (Universidad de Sevilla), Gabriel Travé González, (Universidad de Huelva), Francisco F. Pozuelos Estrada (Universidad de Huelva)

Dirección: Ana Rivero García y Nicolás de Alba Fernández

Técnico de edición: Francisco Javier López Sánchez

\section{Consejo editorial}

José Félix Angulo Rasco. Universidad de Cádiz Rosa Ma Ávila Ruiz. Universidad de Sevilla Pilar Azcárate Goded. Universidad de Cádiz Juan Bautista Martínez Rodríguez. Universidad de Granada

Nieves Blanco García. Universidad de Málaga Fernando Barragán Medero. Universidad de La Laguna José Carrillo Yáñez. Universidad de Huelva José Contreras Domingo. Universidad de Barcelona. Luis C. Contreras González. Universidad de Huelva Ana $\mathbf{M}^{\mathbf{a}}$ Criado García-Legaz. Universidad de Sevilla Rosario Cubero Pérez. Universidad de Sevilla José $\mathbf{M}^{\mathbf{a}}$ Cuenca López. Universidad de Huelva Jesús Estepa Giménez. Universidad de Huelva Rafael Feito Alonso. Universidad Complutense (Madrid)

Francisco José García Gallardo. Universidad de Huelva

Soledad García Gómez. Universidad de Sevilla J. Eduardo García Díaz. Universidad de Sevilla
Fernando Hernández Hernández. Universidad de Barcelona

Salvador Llinares Ciscar. Universidad de Alicante Alfonso Luque Lozano. Universidad de Sevilla Rosa Martín del Pozo. Universidad Complutense (Madrid)

José Martín Toscano. IES Fernando Herrera (Sevilla) Jaume Martínez Bonafé. Universidad de Valencia F. Javier Merchán Iglesias. Universidad de Sevilla Emilia Moreno Sánchez. Universidad de Huelva. Rosario Ortega Ruiz. Universidad de Córdoba Antonio de Pro Bueno. Universidad de Murcia Fco. de Paula Rodríguez Miranda. Universidad de Huelva

Pedro Sáenz-López Buñuel. Universidad de Huelva Antoni Santisteban Fernández. Universidad Autónoma (Barcelona)

Emilio Solís Ramírez. Catedrático de IES. $\mathbf{M}^{\mathbf{a}}$ Victoria Sánchez García. Universidad de Sevilla. Magdalena Suárez Ortega. Universidad de Sevilla

\section{Consejo asesor}

Manuel Area Moreira. Universidad de La Laguna

Jaume Carbonell. Director Cuadernos de Pedagogía. Barcelona

César Coll. Universidad de Barcelona

Christopher Day. Universidad de Nothingham. U.K.

Juan Delval. Universidad Nacional de Educación a Distancia

John Elliott. Universidad de East Anglia. Norwich. U.K.

José Gimeno Sacritán. Universidad de Valencia

André Giordan. Universidad de Paris VII y Ginebra

Francisco Imbernón. Universidad de Barcelona

Ángel Pérez Gómez. Universidad de Málaga

Rafael Porlán Ariza. Universidad de Sevilla

Francesco Tonucci. Instituto de Pedagogía del C.N.R. Roma

Jurjo Torres Santomé. Universidad de A Coruña 
